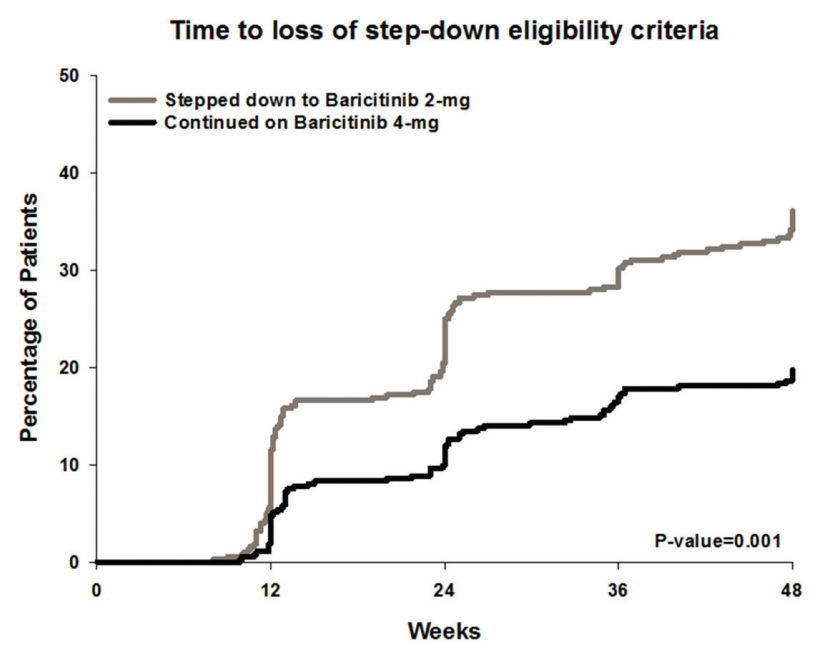

Figure 1. Data represent patients who have completed 48 weeks in the step-down period, or would have completed 48 weeks if not discontinued prior to the data cut-off date (April 1, 2017). Relapse defined as loss of step-down eligibility criteria, CDAI $>10$ for patients originating from RA-BUILD, RA-BEAM, or RA-BEACON. The $p$-value was computed using the Wilcoxon test.

Results: The majority of patients in both groups maintained the state of LDA or REM over the 48 wks. However, dose reduction to 2-mg resulted in significant increases in disease activity at 12,24 , and 48 wks (Table). Dose reduction also resulted in a shorter time to relapse (defined as loss of step-down eligibility criteria); significantly more patients relapsed over 48 wks compared to the 4-mg group (figure 1). Rescue rates were $8.3 \%$ for Bari $4-\mathrm{mg}, 16.6 \%$ for Bari 2-mg. Most rescued patients could regain LDA or REM. Dose reduction was associated with a lower rate of infections; rates of SAEs and AEs leading to discontinuation were similar across groups.

Conclusions: These data indicate that disease control was better maintained with Bari 4-mg than 2-mg. However, most stepped-down patients could maintain LDA or REM, or recapture control with re-introduction of the 4-mg dose. Stepping down to a dose of 2-mg daily may be a viable option for many patients who have achieved sustained LDA or REM on the 4-mg dose.

Disclosure of Interest: T. Takeuchi Consultant for: Pfizer Japan Inc., Astra Zeneca K.K., Eli Lilly Japan K.K., Novartis Pharma K.K., Daiichi Sankyo Co.,Ltd., Nipponkayaku Co.Ltd, Janssen Pharmaceutical K.K., Merck Serono Co.,Ltd., Takeda Pharmaceutical Co., Ltd., Mitsubishi Tanabe Pharma Co., Astellas Pharma Inc, AbbVie GK, Bristol-Myers K.K. Asahi Kasei Medical K.K, Speakers bureau: Celtrion, Nipponkayaku Co.Ltd, Pfizer Japan Inc.,UCB Japan., Diaichi Sankyo Co.,Ltd., Takeda Pharmaceutical Co., Ltd., Chugai Pharmaceutical Co,. Ltd., AbbVie GK., Bristol-Myers K.K., Eisai Co., Ltd., Mitsubishi Tanabe Pharma Co., Janssen Pharmaceutical K.K., and Astellas Pharma Inc, M. Genovese Grant/ research support from: Eli Lilly \& Company, AbbVie, Consultant for: Eli Lilly \& Company, AbbVie, B. Haraoui Grant/research support from: Abbvie, Pfizer, Consultant for: Abbvie, Amgen, Eli Lilly and Company, Merck, Pfizer, UCB, Speakers bureau: Pfizer, UCB, Z. Li: None declared, L. Xie Shareholder of: Eli Lilly and Company, Employee of: Eli Lilly and Company, R. Klar Employee of: IQVIA, A. P. Correia Employee of: Eli Lilly and Company, S. Otawa Employee of: Eli Lilly and Company, P. Lopez-Romero Employee of: Eli Lilly and Company, I. De La Torre Employee of: Eli Lilly and Company, T. Rooney Shareholder of: Eli Lilly and Company, Employee of: Eli Lilly and Company, J. Smolen Grant/research support from: AbbVie, Janssen, Eli Lilly and Company, MSD, Pfizer, Roche, Consultant for: AbbVie, Amgen, Astra-Zeneca, Astro, BMS, Celgene, Celltrion, Chugai, Gilead Glaxo, ILTOO, Janssen, Eli Lilly and Company, Medimmune, MSD, Novartis-Sandoz, Pfizer, Roche, Samsung, Sanofi-Aventis, UCB DOI: 10.1136/annrheumdis-2018-eular.2000

\section{SAT0254 UPADACITINIB IMPROVES PATIENT-REPORTED OUTCOMES IN PATIENTS WITH RHEUMATOID ARTHRITIS AND INADEQUATE RESPONSE TO CONVENTIONAL SYNTHETIC DISEASE-MODIFYING ANTI-RHEUMATIC DRUGS: RESULTS FROM SELECT- NEXT}

V. Strand ${ }^{1}$, J. Pope ${ }^{2}$, N. Tundia ${ }^{3}$, A. Friedman ${ }^{3}$, H. S. Camp ${ }^{3}$, A. Pangan ${ }^{3}$, A. Ganguli ${ }^{3}$, M. Fuldeore ${ }^{3}$, D. Goldschmidt ${ }^{4}$, M. Schiff ${ }^{5}{ }^{1}$ Stanford University, Palo Alto, United States, ${ }^{2}$ University of Western Ontario, London, Canada, ${ }^{3} \mathrm{AbbVie}$ Inc., North Chicago, ${ }^{4}$ Analysis Group, Inc, New York, ${ }^{5}$ University of Colorado, Denver, United States

Background: Upadacitinib (UPA), a selective JAK-1 inhibitor, has demonstrated efficacy in active RA among patients with an inadequate response to conventional synthetic disease-modifying anti-rheumatic drugs (csDMARD-IR). ${ }^{1}$ To understand treatment effectiveness from the patients' perspective we examined the impact of UPA on patient-reported outcomes (PROs).

Objectives: To evaluate the effect of UPA vs placebo (PBO) on PROs in SELECT-NEXT (NCT02675426), a randomized controlled trial assessing the efficacy and safety of UPA in csDMARD-IR RA patients.

Methods: Patients in SELECT-NEXT received UPA $15 \mathrm{mg}$ or $30 \mathrm{mg}$ daily or $\mathrm{PBO}$ for 12 weeks followed by a 5-year extension phase. PROs included physical function (Health Assessment Questionnaire Disability Index [HAQ-DI]), Patient's Global Assessment of Disease Activity (PtGA) by visual analog scale (VAS), pain by VAS, fatigue by FACIT-F, duration and severity of morning (AM) stiffness, quality of life (QoL) by Short Form 36 Health Survey [SF-36], and Work Instability Scale for RA (RA-WIS). Changes in least square means (LSMs) from baseline $(B L)$ to week 12 were based on mixed effect repeated measures models. Percentages of patients reporting changes in PRO scores from BL to week $12 \geq$ minimum clinically important differences (MCIDs) or scores $\geq$ normative values (age- and gender-matched for SF-36 only) were determined for UPA and PBO arms; comparisons between groups used chi-square tests. For each PRO, the incremental number needed to treat (NNT) to achieve clinically meaningful improvement from $\mathrm{BL}(\geq \mathrm{MCID})$ was calculated.

Results: Data from 661 patients (221 in UPA $15 \mathrm{mg} ; 219$ in UPA $30 \mathrm{mg}$; 221 in PBO) were analysed. Mean age was 56 years, $79 \%$ were female; $45 \%$ had RA for $\geq 5$ years. Statistically significant LSM changes from BL to week 12 were reported with both UPA doses vs PBO for HAQ-DI, PtGA, pain, FACIT-F, duration and severity of AM stiffness, SF-36 (PCS; 6 or 7/8 domains), and RA-WIS (Table). Compared with $\mathrm{PBO}$ at week 12 , significantly more UPA-treated (both doses) patients reported improvement $>$ MCID in HAQ-DI, PtGA, pain, FACIT-F, duration and severity of AM stiffness, SF-36 (PCS; 4 or 7/8 domains), and RA-WIS as well as scores $>$ normative values in HAQ-DI, PtGA, FACIT-F, SF-36 (PCS; 4 or $5 / 8$ domains). For most PROs, NNTs with UPA ranged from 4 to 8 patients.

Table 1 LSM changes from baseline and percentage of responders at week 12 after UPA initiation

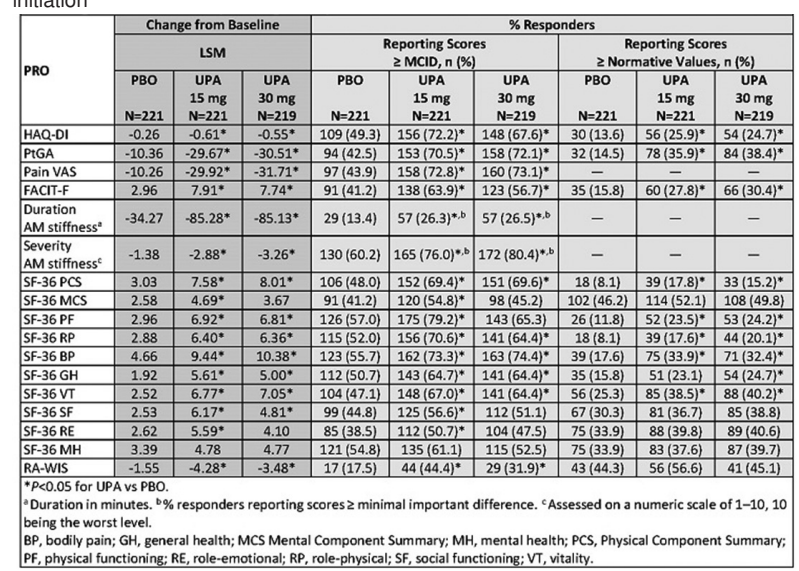

Conclusions: Treatment with UPA $15 \mathrm{mg}$ or $30 \mathrm{mg}$ daily for 12 weeks resulted in significant and clinically meaningful improvements in physical function, pain, fatigue, AM stiffness, QoL, and less work instability among csDMARD-IR RA patients. The NNTs to achieve these improvements were favourable. 


\section{REFERENCE:}

[1] Burmester, et al. Arthritis Rheumatol 2017:69(suppl 10), abstract 1904.

Acknowledgements: Financial support for the study was provided by AbbVie. AbbVie participated in the interpretation of data, review, and approval of the abstract. All authors contributed to the development of the publication and maintained control over the final content. Medical writing services were provided by Joann Hettasch of Fishawack Communications and funded by AbbVie.

Disclosure of Interest: V. Strand Consultant for: AbbVie, Amgen, AstraZeneca, BMS, Celgene, Genentech, GSK, Janssen, Lilly, Novartis, Pfizer, Regeneron, Sanofi, and UCB, J. Pope Consultant for: AbbVie, Amgen, BMS, Celltrion, GSK, Lilly, Merck, Novartis, Pfizer, Roche, Sanofi, Sandoz, UCB, N. Tundia Shareholder of: AbbVie, Employee of: AbbVie, A. Friedman Shareholder of: AbbVie, Employee of: AbbVie, H. Camp Shareholder of: AbbVie, Employee of: AbbVie, A. Pangan Shareholder of: AbbVie, Employee of: AbbVie, A. Ganguli Shareholder of: AbbVie, Employee of: AbbVie, M. Fuldeore Shareholder of: AbbVie, Employee of: AbbVie, D. Goldschmidt Employee of: Analysis Group, Inc., which received consulting fees from AbbVie for this study, M. Schiff Consultant for: Abbvie, BMS, Eli Lilly, JNJ, UCB, Speakers bureau: AbbVie, BMS

DOI: 10.1136/annrheumdis-2018-eular.1202

\section{SAT0255 PATIENT REPORTED OUTCOMES OF UPADACITINIB: RESULTS FROM BIOLOGIC INADEQUATE RESPONDERS (SELECT BEYOND PHASE III TRIAL)}

V. Strand ${ }^{1}$, M. Schiff ${ }^{2}$, N. Tundia ${ }^{3}$, A. Friedman ${ }^{3}$, S. Meerwein ${ }^{3}$, A. Pangan ${ }^{3}$, A. Ganguli ${ }^{3}$, M. Fuldeore ${ }^{3}$, Y. Song ${ }^{4}$, J. Pope ${ }^{5} .{ }^{1}$ Stanford University, Palo Alto; ${ }^{2}$ University of Colorado, Denver, ${ }^{3}$ AbbVie Inc., North Chicago; ${ }^{4}$ Analysis Group, Inc., Boston, USA; ${ }^{5}$ University of Western Ontario, London, Canada

Background: Patient reported outcomes (PROs) were studied in patients with active rheumatoid arthritis (RA) who had an inadequate response to biologic disease modifying anti-rheumatic drugs (bDMARD-IR) in a trial of upadacitinib (UPA), a selective JAK-1 inhibitor. Improvements in PROs are important when evaluating comprehensive efficacy of treatments for RA.

Objectives: The objective of this post-hoc analysis was to compare PRO responses and numbers needed to treat (NNT) in order to assess clinically meaningful improvements in bDMARD-IR patients with RA receiving UPA.

Methods: Data from the SELECT BEYOND randomised controlled trial (RCT) (NCT02706847) were used to compare PRO responses between UPA (15 mg QD and $30 \mathrm{mg} Q D$ ) and PBO. PROs included physical function by Health Assessment Questionnaire Disability Index (HAQ-DI), Patient's Global Assessment of Disease Activity (PtGA) by visual analogue scale (VAS), pain by VAS, duration and severity of morning (AM) stiffness, health-related quality of life by Short Form 36 Health Survey (SF-36), and severity of insomnia by Insomnia Severity Index (ISI). Changes in least squares means (LSM) from baseline to week 12 were based on mixed effect repeated measures models. Percentages of patients reporting changes in PRO scores from baseline to week $12 \geq$ minimum clinically important difference (MCID) values or scores $\geq$ normative values (age- and gender-matched for SF-36 only) were determined; comparisons between groups used chi-square tests. For each PRO measure, the incremental NNT to achieve clinically meaningful improvements from baseline $(\geq M C I D)$ was calculated.

Abstract SAT0255 - Table 1. LSM Changes From Baseline and Percentage of Responders at Week 12

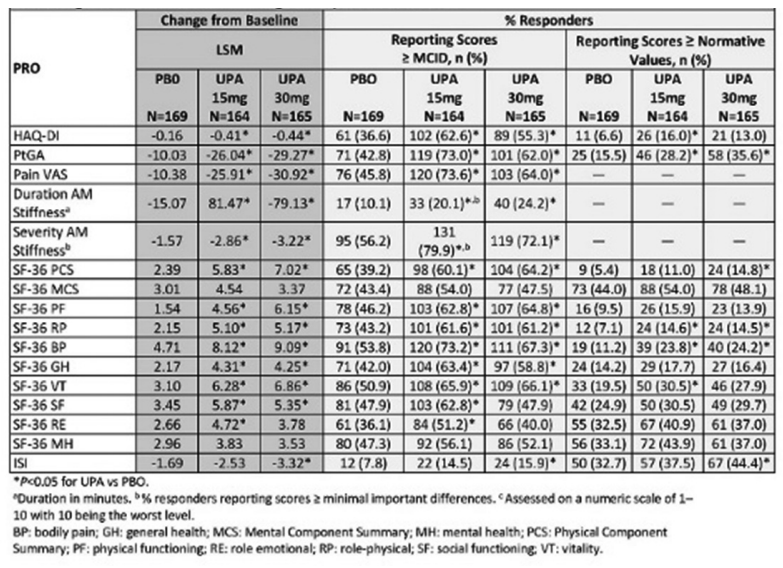

Results: Data from 498 patients (169 in PBO, 164 in UPA 15 mg, 165 in 30 mg UPA) were analysed. Mean age was 57 years, $84 \%$ were females, and $55 \%$ had RA for $\geq 10$ years. Both UPA doses resulted in statistically significant LSM changes from baseline vs PBO in HAQ-DI, PtGA, pain, duration and severity of AM stiffness, SF-36 Physical Component Summary (PCS), 7/8 domains (15 mg), and 6/8 domains (30 mg) (Table). Compared with PBO at week 12, UPA-treated patients reported higher responses that were statistically significant and clinically meaningful for HAQ-DI, PtGA, pain, duration and severity of AM stiffness, SF-36 PCS, 7/8 domains (15 mg), 5/8 domains $(30 \mathrm{mg})$, and ISI $(30 \mathrm{mg})$. The Table presents the proportion of patients reporting scores that were $\geq$ normative values at week 12. Across most PROs, the NNTs with UPA ranged from 4 to 7 patients. Conclusions: This RCT demonstrated that even in difficult-to-treat bDMARD-IR patients with active RA, treatment with UPA resulted in significantly more patients with clinically meaningful improvements in PROs or responses that approached normative values. The NNT to achieve a meaningful response was favourable. Acknowledgements: Financial support for the study was provided by AbbVie. AbbVie participated in the interpretation of data, review, and approval of the abstract. All authors contributed to the development of the publication and main tained control over the final content. Medical writing services were provided by Lourdes Yun of Fishawack Communications and funded by AbbVie.

Disclosure of Interest: V. Strand Consultant for: AbbVie, Amgen, AstraZeneca, BMS, Celgene, Genentech, GSK, Janssen, Lilly, Novartis, Pfizer, Regeneron, Sanofi, and UCB, M. Schiff Consultant for: Abbvie, BMS, Eli Lilly, JNJ, UCB, Speakers bureau: AbbVie and BMS, N. Tundia Shareholder of: AbbVie Employee of: AbbVie, A. Friedman Shareholder of: AbbVie, Employee of: AbbVie, S. Meerwein Shareholder of: AbbVie, Employee of: AbbVie, A. Pangan Share holder of: AbbVie, Employee of: AbbVie, A. Ganguli Shareholder of: AbbVie, Employee of: AbbVie, M. Fuldeore Shareholder of: AbbVie, Employee of: AbbVie, Y. Song Employee of: Analysis Group, Inc., which received consulting fees from AbbVie for this study, J. Pope Consultant for: AbbVie, Amgen, BMS, Celltrion, GSK, Lilly, Merck, Novartis, Pfizer, Roche, Sanofi, Sandoz, UCB DOI: 10.1136/annrheumdis-2018-eular.1254

\section{SAT0256 1 TOFACITINIB WITH AND WITHOUT METHOTREXATE VERSUS ADALIMUMAB WITH METHOTREXATE FOR THE TREATMENT OF RHEUMATOID ARTHRITIS: PATIENT-REPORTED OUTCOMES FROM A PHASE 3B/4 RANDOMISED TRIAL}

V. Strand ${ }^{1}$, E. Mysler ${ }^{2}$, R.J. Moots ${ }^{3}$, G. Wallenstein ${ }^{4}$, R. DeMasi ${ }^{5}$, D. Gruben ${ }^{4}$, K. Soma ${ }^{4}$, N. likuni 6 , R. Fleischmann ${ }^{7}{ }^{1}$ Division of Immunology/Rheumatology, Stanford University, Palo Alto, CA, USA; ${ }^{2}$ Organización Médica de Investigación, Buenos Aires, Argentina; ${ }^{3}$ Institute of Ageing and Chronic Disease, University of Liverpool, Liverpool, UK; ${ }^{4}$ Pfizer Inc, Groton, CT; ${ }^{5}$ Pfizer Inc, Collegeville, PA ${ }^{6}$ Pfizer Inc, New York, NY; ${ }^{7}$ Metroplex Clinical Research Center and University of Texas Southwestern Medical Center, Dallas, TX, USA

Background: Tofacitinib is an oral Janus kinase inhibitor for the treatment of rheumatoid arthritis (RA).

Objectives: To compare patient-reported outcomes (PROs) among patients receiving tofacitinib monotherapy, tofacitinib +methotrexate (MTX) and adalimu mab (ADA) +MTX, in a head-to-head trial of patients with RA and inadequate responses to MTX (MTX-IR).

Methods: ORAL Strategy (NCT02187055) was a Phase 3b/4, 1 year, triple dummy, active randomised controlled trial (RCT). Patients were randomised 1:1:1 to receive tofacitinib $5 \mathrm{mg}$ twice daily (BID; tofa mono), tofacitinib $5 \mathrm{mg} \mathrm{BID+MTX}$ (tofa + MTX) or subcutaneous ADA 40 mg every other week +MTX (ADA +MTX) MTX doses were 15-25 mg/wk. PROs (secondary endpoints in this RCT) assessed at Months (Mos) 6 and 12 included mean changes from baseline in patient global assessment of disease activity (visual analogue scale [VAS]); arthritis pain (VAS); Health Assessment Questionnaire-Disability Index (HAQ-DI) Short Form-36 Health Survey; EuroQol 5-dimensions Questionnaire; Work Productivity and Activity Impairment Questionnaire; Functional Assessment of Chronic Illness Therapy-Fatigue; and the proportion of patients reporting improvements in HAQ-DI > minimum clinically important difference (MCID; -0.22 ). Nominal $p$ values were calculated with no adjustment for multiple comparisons

Results: Among 1146 patients treated (tofa mono: $n=384$; tofa +MTX: $n=376$; ADA+MTX: $n=386$ ), baseline demographics and disease characteristics were comparable. At Mos 6 and 12, improvements in all PROs were similar for tofa +MTX and ADA+MTX (there were essentially no differences based on nominal $p$ values) and numerically greater than with tofa mono (Table). Mean changes from baseline in HAQ-DI scores were similar in each treatment group at Mos 6 and 12; similar proportions reported improvements $\geq \mathrm{MCID}$ 